\title{
Caregivers' Willingness to Vaccinate Their Children Against COVID-19 in Saudi Arabia: A Cross-Sectional Survey
}

Zainab Almusbah ${ }^{1}$, Zahraa Alhajji ${ }^{1}$, Zahraa Alshayeb ${ }^{1}$, Rania Alhabdan ${ }^{1}$, Sukainah Alghafli ${ }^{1}$, Mohammed Almusabah ${ }^{2}$, Fatimah Almuqarrab ${ }^{3}$, Isra Aljazeeri ${ }^{4}$, Fida Almuhawas ${ }^{5}$

1. College of Medicine, King Faisal University, Al-Ahsa, SAU 2. General Surgery, King Fahad General Hospital, Al-Ahsa, SAU 3. Dermatology, King Fahad General Hospital, Al-Ahsa, SAU 4. Otology, King Abdullah Ear Specialist Center (KAESC) College of Medicine, King Saud University Medical City (KSUMC) King Saud University, Riyadh, SAU 5. Otorhinolaryngology - Head \& Neck, King Abdullah Ear Specialist Center (KAESC) King Abdulaziz University Hospital, King Saud University, Riyadh, SAU

Corresponding author: Isra Aljazeeri, dr.isra.aljazeeri@gmail.com

\section{Abstract}

\section{Background}

In early 2021, vaccination against COVID-19 became one of the most important measures needed to control the pandemic.

\section{Objectives}

This study aimed to investigate the levels of acceptance and factors affecting the decisions among Saudi parents and caregivers of children under 12 for getting them vaccinated.

\section{Design and setting}

A cross-sectional survey of 1000 caregivers and parents was carried out from May 2021 to June 2021. The participants were from the eastern, central, southern, western, and northern provinces of Saudi Arabia.

\section{Materials and methods}

The data were collected and managed using Microsoft Excel (Microsoft ${ }^{\circledR}$ Corp., Redmond, WA) and analyzed using SPSS version 23 (IBM Corp., Armonk, NY).

\section{Results}

Of the 1000 respondents, 281 (28.1\%) reported they would vaccinate their children, 346 (34.6\%) rejected vaccination, and $373(37.3 \%)$ were not sure. Most caregivers $(24.1 \% ; n=241)$ reported protecting children as

Review began 07/16/2021 Review ended 08/15/2021 Published 08/17/2021

\section{() Copyright 2021}

Almusbah et al. This is an open access article distributed under the terms of the Creative Commons Attribution License CC-BY 4.0., which permits unrestricted use, distribution, and reproduction in any medium, provided the original author and source are credited. the principal reason for accepting vaccination. Regarding those rejecting the vaccine, the most common concern was that children might experience side effects $(42.9 \%$; $=429)$.

\section{Limitations}

The acceptance of the COVID-19 vaccine is dynamic and changes with legislations and public awareness policies.

\section{Conclusions}

COVID-19 vaccine acceptance for children was low at the time of this study compared to the United Kingdom and United States. To achieve vaccination coverage that is adequate for herd immunity in Saudi Arabia, intense educational and awareness strategies are needed.

Categories: Pediatrics, Preventive Medicine, Infectious Disease

Keywords: covid-19, coronavirus, vaccines, pediatrics, saudi arabia

\section{Introduction}

COVID-19 was first reported to the WHO on December 31, 2019, in Wuhan City, Hubei Province, China. On March 11, 2020, the WHO declared COVID-19 as a global pandemic [1,2]. Since then, protective measures have been instituted worldwide to control the spread of the disease. For any infectious disease, the availability of safe and effective vaccines is important for establishing herd immunity and preventing infection spread [3]. At the time of writing this paper, at least seven vaccines were approved by most countries. Over 200 candidate vaccines are at some stage of development, and at least 60 of these are at the 
clinical development stage [4]. Vaccine candidates are targeted for use in outbreak settings and provide long-term protection for those at risk of COVID-19, such as health care workers [5].

During a pandemic, conventional vaccine approval processes may be waived. For instance, some vaccine candidates have been granted fast-track licensure by the US Food and Drug Administration [6]. Even when safe and effective vaccines have been developed, a major barrier to reaching herd immunity is community acceptance for getting vaccinated. Hesitancy levels and reasons vary in different communities, depending on the nature of the vaccines, health care systems, accessibility, and cultural and social factors. Evidence shows that the newer the vaccine, the higher the hesitancy level among the public, which may pose a major challenge for persuading people to get a COVID-19 vaccine [7].

Recent studies have been conducted on different populations to determine the acceptance of COVID-19 vaccines. In the United Kingdom, 55.8\% of survey respondents said they would accept vaccination for themselves, and $48 \%$ would accept it for their children [8]. In the United States, $80 \%$ of Americans reported that they would accept the vaccination for themselves and their children [9]. In another international study investigating global caregivers' intentions, $65.2 \%$ of respondents reported that they are planning to vaccinate their children [10]. According to the evidence, the most consistent reason for COVID-19 vaccine hesitancy is the novelty of the vaccines. The other two main determinants of caregivers' hesitancy toward vaccinating children are safety concerns and the perception that children are rarely affected by COVID-19 [8-10].

In Saudi Arabia, a study conducted on the adult population demonstrated a $64.7 \%$ acceptance of a hypothetical vaccine. Participants' trust in the health system and the perceived risk of getting infected were two major determining factors for this willingness [11]. However, the willingness of caregivers to get their children vaccinated and the determinants of vaccine hesitancy need to be investigated to plan a vaccination program once vaccines are available. To the best of our knowledge, this study is the first of its kind in Saudi Arabia.

\section{Materials And Methods Study design and setting}

The present study was a cross-sectional survey of the Saudi population from the eastern, central, southern, western, and northern provinces. It investigated the factors that affect parents' and family caregivers' acceptance of COVID-19 vaccines for their children. This study was approved by the research ethics committee of the University Hospital (approval number E-20-5558). After the participation details were explained, informed consent was provided by all participants before proceeding to the survey link.

The study was carried out from May 12th, 2021 to June 28th, 2021. Eligible participants were Saudi parents and caregivers of one child or more aged up to 12 years; participants who did not complete the entire survey were excluded. The survey was designed using Google Forms, and the data were collected in an encrypted Google drive. Distribution was via a link on social media channels (Twitter, WhatsApp, and Telegram). The respondents were asked for their socio-demographic characteristics, the health status of their children, commitment to the national vaccination program, and their beliefs about COVID-19 vaccines. The second part of the survey evaluated their level of vaccine hesitancy and the reasons for their decisions regarding vaccination.

\section{Survey design and pre-testing}

The survey items were extracted from a similar study conducted with a British population [8]. The survey was translated by two bilingual health-science researchers and reviewed by two other bilingual researchers. The translated survey was then distributed among 10 randomly chosen participants to examine its comprehensibility, time taken, and any technical problems with the survey link. The reviewed survey was then distributed to the target population.

\section{Analysis}

The data were collected and managed using Microsoft Excel version 16.3 (Microsoft ${ }^{\circledR}$ Corp., Redmond, WA) and analyzed using SPSS version 23 (IBM Corp., Armonk, NY). Statistical significance, confidence interval, and study power were set at $\mathrm{p}<0.05,95 \%$, and $80 \%$, respectively. Percentage was used for the descriptive values. Chi-square was used to evaluate the differences between categorical variables, and a paired t-test was used to compare the willingness to vaccinate oneself and willingness to vaccinate their children.

\section{Results}

The study included 1000 parents and caregivers (Table 1). Most survey participants lived in the eastern provinces $(64.1 \% ; n=641)$, followed by the central $(17.8 \% ; n=178)$, western $(8.9 \% ; n=89)$, southern $(8.4 \%$; $\mathrm{n}=84)$, and northern $(5 \% ; \mathrm{n}=5)$ provinces. Of 1000 parents and caregivers, $788(78.8 \%)$ were female, and most were the children's mothers $(65.8 \% ; \mathrm{n}=658)$. This gender imbalance in our study sample likely affected the robustness of the study's findings, since most of the reported vaccine rejections were from 


\section{Cureus}

female caregivers. Most children had received the vaccinations appropriate for their age, as per the national immunization program $(78.9 \% ; n=789)$. Regarding the medical histories of the children, most $(92.8 \% ; n=$ 928) did not have any chronic diseases. Furthermore, 960 (96.9\%) children did not use regular medication, and most children had not had COVID-19 (89.4\%; $n=894)$. Only $243(24.3 \%)$ of the parents and caregivers had been vaccinated against seasonal flu in the current year, and $476(47.6 \%)$ had never been vaccinated against seasonal flu (Table 2).

\begin{tabular}{|c|c|c|}
\hline Characteristics & & Frequency (\%) \\
\hline \multirow{5}{*}{ Residence } & Eastern province & $641(64.1 \%)$ \\
\hline & Central provınce & $1 / 8(17.8 \%)$ \\
\hline & Western province & $89(8.9 \%)$ \\
\hline & South province & $84(8.4 \%)$ \\
\hline & North province & $5(0.5 \%)$ \\
\hline \multirow{5}{*}{ Relationship with child } & Mother & $658(65.8 \%)$ \\
\hline & Father & 194 (19.4\%) \\
\hline & Sibling & $76(7.6 \%)$ \\
\hline & Aunt/uncle & $60(6 \%)$ \\
\hline & Grandparents & $12(1.2 \%)$ \\
\hline \multirow{2}{*}{ Gender of caregiver } & Female & $788(78.8 \%)$ \\
\hline & Male & $212(21.2 \%)$ \\
\hline \multirow{4}{*}{ Age of child } & Newborn to 30 days & $14(1.4 \%)$ \\
\hline & One month to 2 years & $232(23.2 \%)$ \\
\hline & 2 years to 6 years & $402(40.2 \%)$ \\
\hline & 6 years to 12 years & $352(35.2 \%)$ \\
\hline \multirow{2}{*}{ Gender of child } & Female & $470(47 \%)$ \\
\hline & Male & $530(53 \%)$ \\
\hline \multirow{2}{*}{ Chronic diseases } & Yes & $72(7.2 \%)$ \\
\hline & No & $928(92.8 \%)$ \\
\hline \multirow{2}{*}{ Medications } & Yes & $40(4 \%)$ \\
\hline & No & $960(96 \%)$ \\
\hline \multirow{3}{*}{ Child has received age-appropriate vaccinations } & Yes & $786(78.6 \%)$ \\
\hline & No & $117(11.7 \%)$ \\
\hline & Not sure & $97(9.7 \%)$ \\
\hline \multirow{2}{*}{ Caregiver has received seasonal flu vaccine this year } & Yes & $243(24.3 \%)$ \\
\hline & No & $757(75.7 \%)$ \\
\hline \multirow{2}{*}{ Caregiver has ever received seasonal flu vaccine } & Yes & $476(47.6 \%)$ \\
\hline & No & $524(52.4 \%)$ \\
\hline \multirow{2}{*}{ Child ever infected with COVID-19 } & Yes & $106(10.6 \%)$ \\
\hline & No & 894 (89.4\%) \\
\hline
\end{tabular}

TABLE 1: Characteristics of the study population. 


\section{Cureus}

\begin{tabular}{|c|c|c|c|c|c|c|}
\hline \multirow{2}{*}{ Variables } & \multicolumn{3}{|c|}{$\begin{array}{l}\text { Are you willing to get the COVID-19 vaccine if } \\
\text { approved by the Saudi FDA? }\end{array}$} & \multicolumn{3}{|c|}{$\begin{array}{l}\text { Are you willing to get the COVID-19 vaccine for your child } \\
\text { if approved by the Saudi FDA? }\end{array}$} \\
\hline & Yes & $\begin{array}{l}\text { Pearson Chi-Square (2-sided } \\
\text { significance) }\end{array}$ & $\begin{array}{l}95 \% \\
\mathrm{Cl}\end{array}$ & Yes & $\begin{array}{l}\text { Pearson Chi-Square (2-sided } \\
\text { significance) }\end{array}$ & $95 \% \mathrm{Cl}$ \\
\hline \multicolumn{7}{|l|}{ Residence } \\
\hline $\begin{array}{l}\text { Eastern } \\
\text { province }\end{array}$ & $26.80 \%$ & \multirow{5}{*}{$11.77(p=0.15)$} & \multirow{5}{*}{$\begin{array}{l}0.12- \\
0.18\end{array}$} & $25.30 \%$ & \multirow{5}{*}{$3.04(p=0.93)$} & \multirow{5}{*}{$0.91-0.95$} \\
\hline $\begin{array}{l}\text { Central } \\
\text { province }\end{array}$ & $33.70 \%$ & & & $28.10 \%$ & & \\
\hline $\begin{array}{l}\text { Western } \\
\text { province }\end{array}$ & $29.20 \%$ & & & $27 \%$ & & \\
\hline $\begin{array}{l}\text { South } \\
\text { province }\end{array}$ & $23.80 \%$ & & & $20.20 \%$ & & \\
\hline $\begin{array}{l}\text { North } \\
\text { province }\end{array}$ & $37.50 \%$ & & & $37.50 \%$ & & \\
\hline \multicolumn{7}{|c|}{ Relationship with child } \\
\hline Mother & $23.90 \%$ & \multirow{5}{*}{$22.55(p=0.005)$} & \multirow{5}{*}{$\begin{array}{l}0.00- \\
0.01\end{array}$} & $21.30 \%$ & \multirow{5}{*}{$20.7(p=0.006)$} & \multirow{5}{*}{$0.00-0.01$} \\
\hline Father & $37.10 \%$ & & & $35.60 \%$ & & \\
\hline Sibling & $32.90 \%$ & & & $30.30 \%$ & & \\
\hline Aunt/Uncle & $38.30 \%$ & & & $33.30 \%$ & & \\
\hline Grandparents & $33.30 \%$ & & & $33.30 \%$ & & \\
\hline \multicolumn{7}{|c|}{ Gender of caregiver } \\
\hline Female & $25.90 \%$ & $10.18(p=0.007)$ & $\begin{array}{l}0.00- \\
0.01\end{array}$ & $23 \%$ & $13.54(p=0.001)$ & $\begin{array}{l}0.00- \\
0.004\end{array}$ \\
\hline \multicolumn{7}{|l|}{ Age of child } \\
\hline $\begin{array}{l}\text { Newborn to } 1 \\
\text { month }\end{array}$ & & & & $21.40 \%$ & \multirow{4}{*}{$2.88(p=0.82)$} & \multirow{4}{*}{$0.79-0.85$} \\
\hline $\begin{array}{l}1 \text { month to } 2 \\
\text { years }\end{array}$ & & & & $25.9 \%$ & & \\
\hline 2-6 years old & & & & $24.40 \%$ & & \\
\hline $\begin{array}{l}6-12 \text { years } \\
\text { old }\end{array}$ & & & & $27 \%$ & & \\
\hline \multicolumn{7}{|c|}{ Chronic Disease } \\
\hline Present & & & & $25.80 \%$ & \multirow{2}{*}{$1.23(p=0.52)$} & \multirow{2}{*}{$0.48-0.56$} \\
\hline Absent & & & & $23.60 \%$ & & \\
\hline \multicolumn{7}{|l|}{ Medication } \\
\hline Present & & & & $25.10 \%$ & \multirow{2}{*}{$3.44(P=0.18)$} & 0.15 \\
\hline Absent & & & & $37.50 \%$ & & 0.21 \\
\hline \multicolumn{7}{|c|}{ Child has recelved age-appropriate vaccinations } \\
\hline No & $28.20 \%$ & & & $25.60 \%$ & \multirow{2}{*}{$3.88(P=0.43)$} & 0.39 \\
\hline Yes & $28.90 \%$ & & & $26.50 \%$ & & 0.47 \\
\hline \multicolumn{7}{|c|}{ Caregiver has received seasonal flu vaccination this year } \\
\hline No & $23.10 \%$ & & & $20.90 \%$ & & 0 \\
\hline
\end{tabular}




\section{Cureus}

$43.60 \%$

$40.30 \%$

Caregiver has received seasonal flu vaccination ever

No

$22.90 \%$

Yes

$33.80 \%$

$21 \%$

$30.70 \%$

$12.78(P=0.002)$

0.005

Yes

$25.70 \%$

$0.51(P=0.78)$

$24.50 \%$

0.66

$0.84(P=0.62)$

0.66

$25.40 \%$

0.86

TABLE 2: Variables and categories among the study population.

Of the 1000 respondents, 281 (28.1\%) said that they would get vaccinated, 346 (34.6\%) rejected vaccination, and $373(37.3 \%)$ reported they were not yet sure of their decision. Additionally, 256 (25.6\%) agreed to get their child vaccinated, 370 (37\%) rejected vaccination of their child, and $374(37.4 \%)$ reported they were not yet sure of their decision (Figure 1).
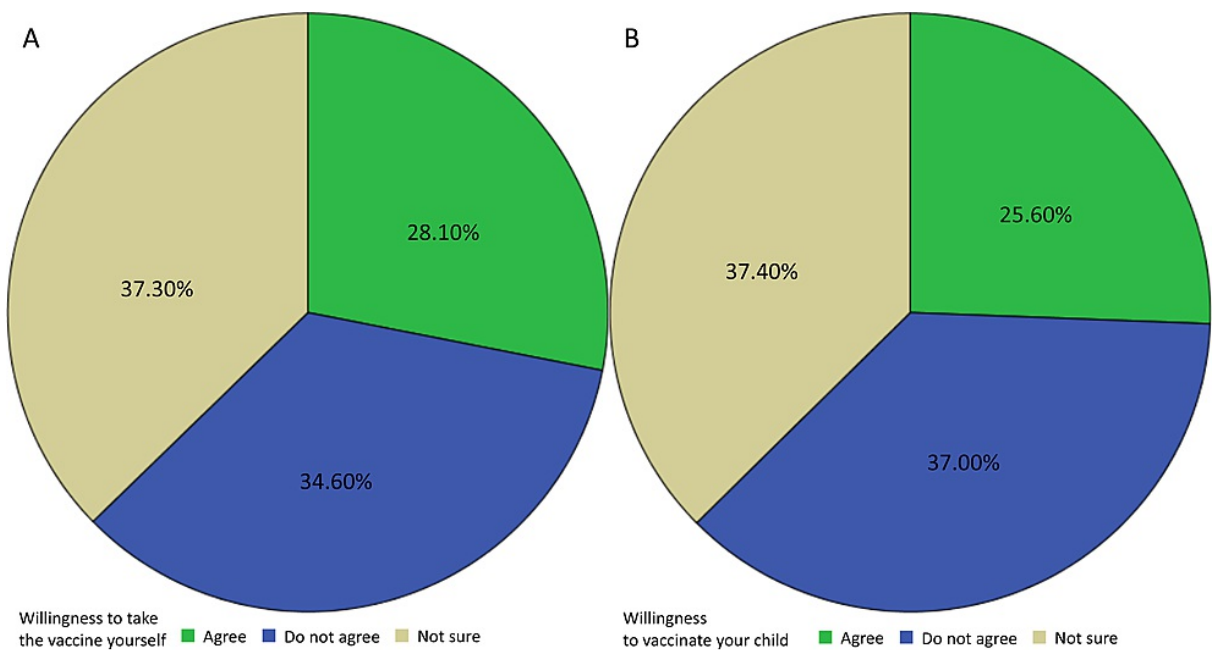

FIGURE 1: (A) Caregivers' willingness to be vaccinated; (B) Caregivers' willingness to vaccinate their children.

No differences were found in vaccine acceptance for themselves or the children among the different provinces (chi-square p-values 0.15 and 0.93 , respectively). Mothers' and females' acceptance rates (23.9\% 
and $25.9 \%$, respectively) were the lowest for accepting a COVID-19 vaccine for themselves or their children. Those who received the seasonal flu vaccine in the current year or had ever received it had significantly higher acceptance rates for getting vaccinated $(\mathrm{p}<0.001)$ (Figures 2, 3).

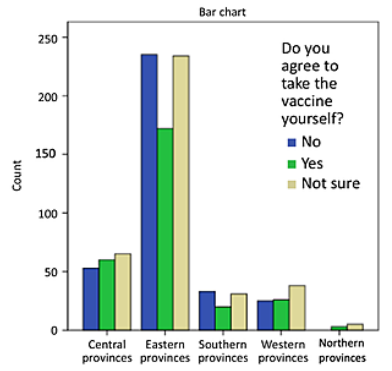

Residence

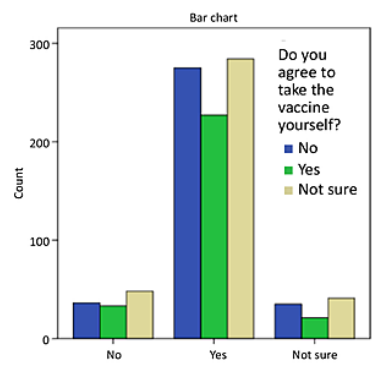

Has the child been vaccinated according to national vaccination schedule?

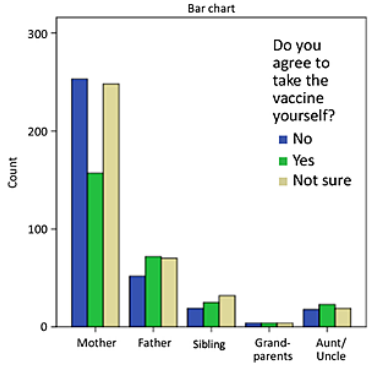

Relation to the child

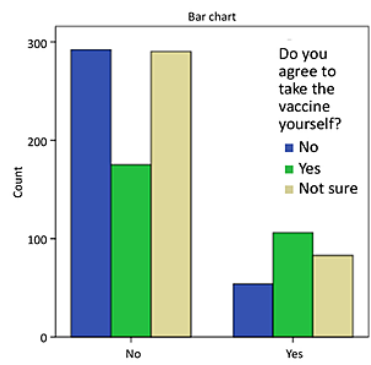

Did you receive the seasonat flu vaccine this year?

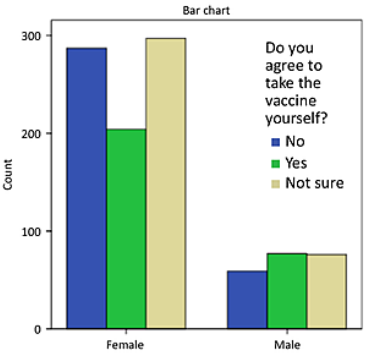

Gender of the caregiver who answered the questionnaire

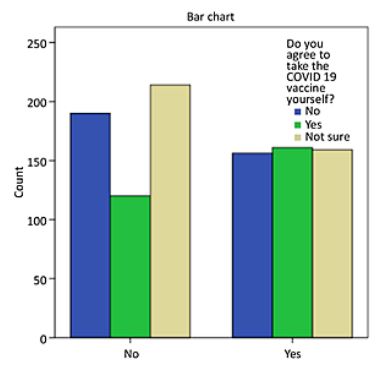

Did you receive the seasonal flu vaccine yourself?

FIGURE 2: Caregivers' willingness to be vaccinated in relation to their demographic information.
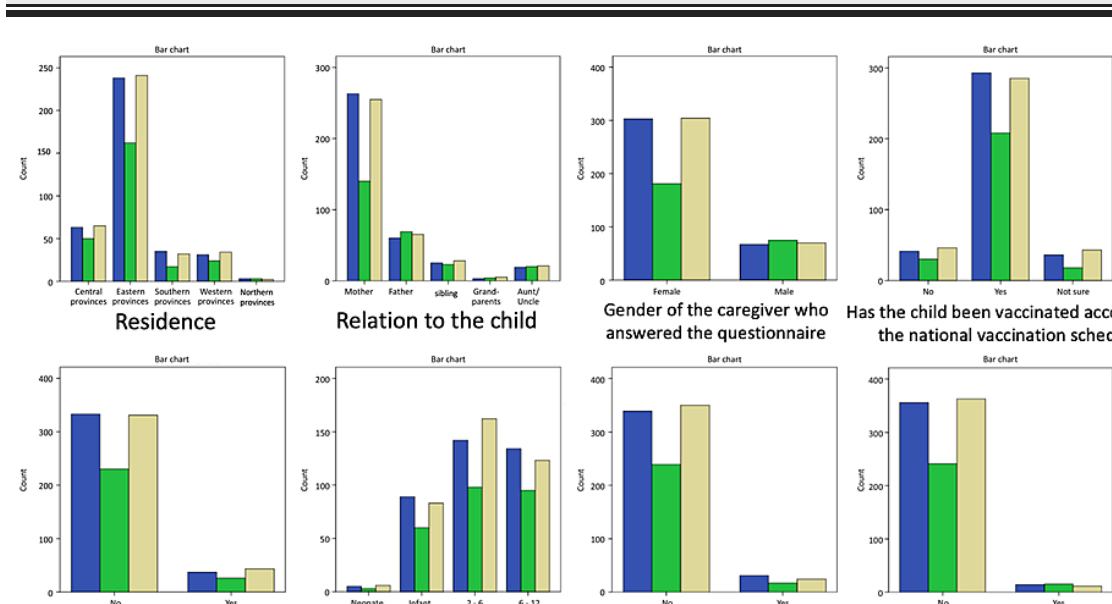

Did your child get infected with the COVID-19?
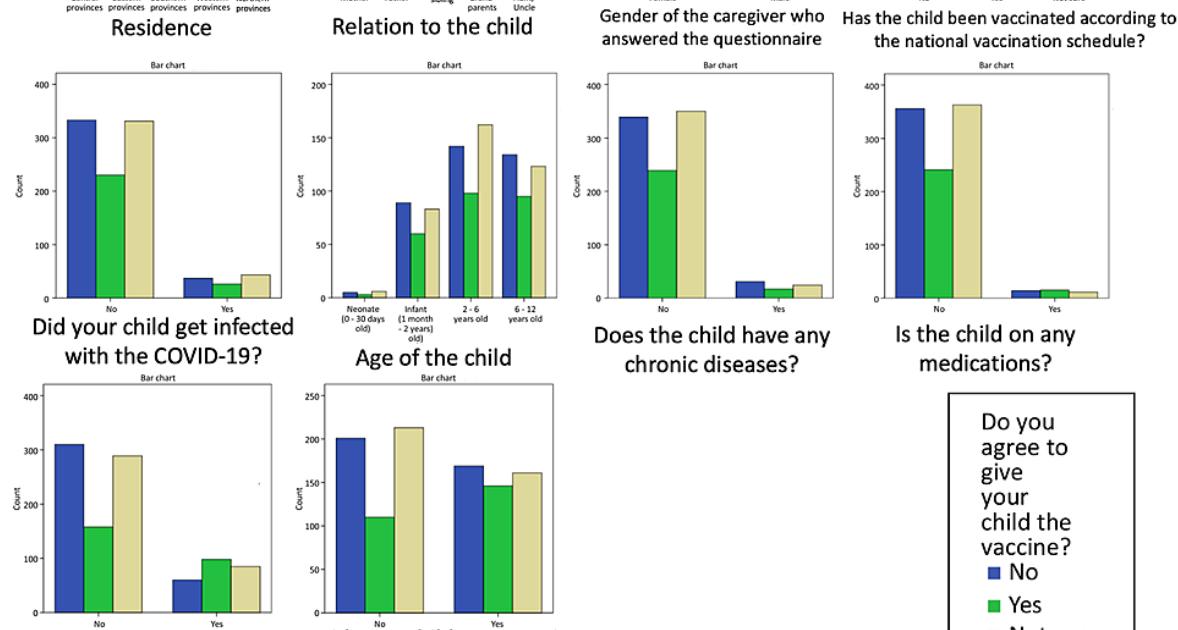
chronic diseases? medications?

your child receive the Did your child ever receive

Do you
agree to
give
your
child the
vaccine?
$\square$ No
$\square$ Yes
$\square$ Not sure

FIGURE 3: Caregivers' willingness to vaccinate their children in relation to their demographic information.

The acceptance rate for vaccinating the child was not significantly different among different age groups (chi- 
square p-value 0.82 ). Whether the child had any chronic diseases, took prescribed medications, had up-todate vaccinations, or had been infected with COVID-19, had no significant effects on the decision to vaccinate the child ( $\mathrm{p}=0.52,0.18$, and 0.43 , respectively). Most of the survey participants had a good awareness of COVID-19 prevention methods. Social distancing, handwashing, and wearing masks were believed to be important protective measures by $94.2 \%, 96 \%$, and $93.6 \%$ of the participants, respectively. Despite their beliefs in these preventative measures, the rate of acceptance for oneself or their child getting vaccinated was not significantly different from those participants who did not believe in the preventative measures ( $\mathrm{p}=0.17$ to 0.9 ).

Protection of the child was the principal reason that most caregivers accepted vaccination $(24.1 \% ; \mathrm{n}=241)$. On the other hand, the most common concern expressed by survey participants who rejected vaccination was the side effects of the vaccine $(42.9 \% ; \mathrm{n}=429)$ (Figures 4,5$)$.

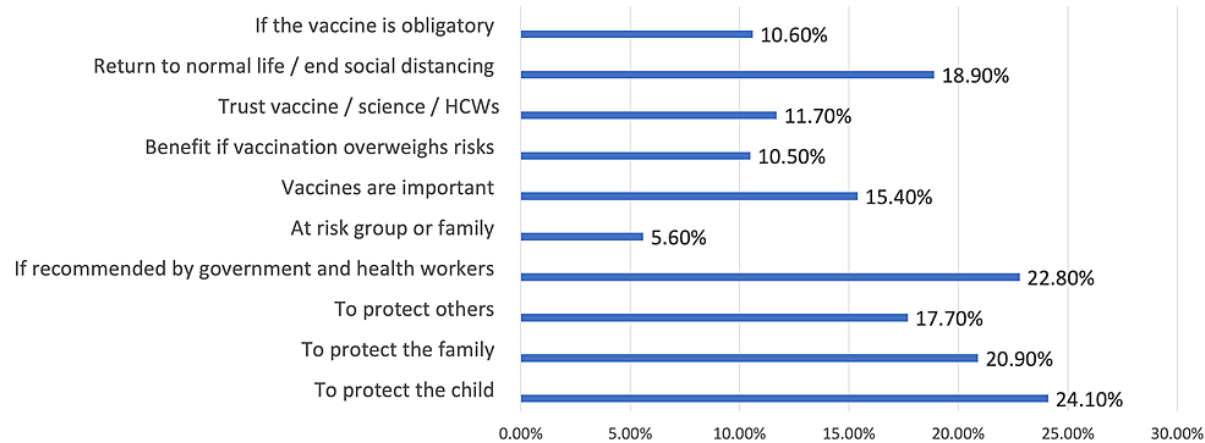

\section{FIGURE 4: Caregivers' reasons for vaccinating their children against COVID-19.}

HCWs: Health care workers

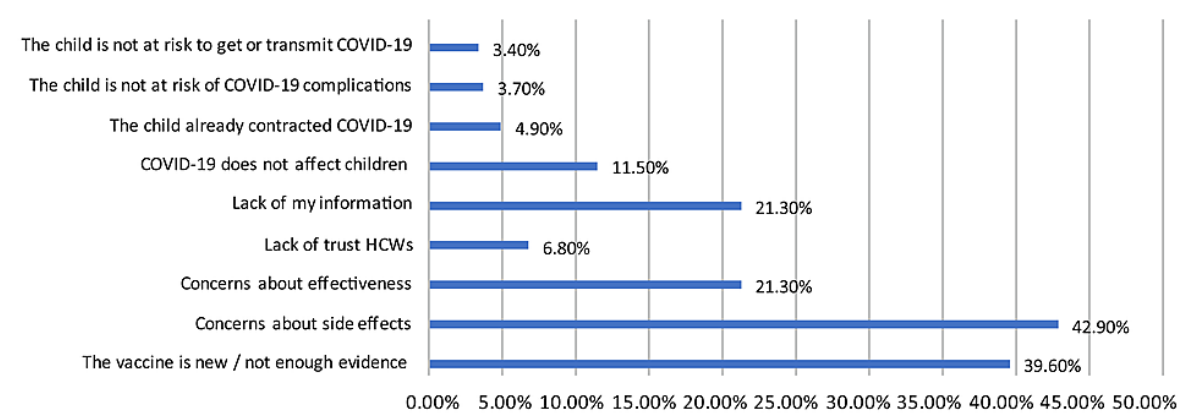

FIGURE 5: Caregivers' reasons for not vaccinating their children against COVID-19.

HCWs: Health care workers

\section{Discussion}

Vaccinations have some of the most remarkable public health benefits. In the case of COVID-19, it may be the most feasible way to end the pandemic and reach herd immunity [3]. However, vaccine hesitancy is a major challenge when bringing vaccination programs into communities. In this cross-sectional study, COVID-19 vaccine hesitancy and acceptance were investigated, and our study results skewed toward rejecting vaccination. Our findings demonstrate that around $25 \%$ of respondents were willing to vaccinate their children, which is in contrast to American and British surveys, which found that $80 \%$ and $89 \%$ of parents were willing to vaccinate their children, respectively [8-10].

Additionally, in contrast to the previously reported independent factors [10], child's age, being up-to-date on vaccinations, and the child's medical and medication histories, were not found to significantly affect participants' willingness to vaccinate their children. In parallel with Goldman et al.'s study on H1N1 vaccination willingness [12], our data demonstrate a preferential acceptance rate among male compared to 
female parents and caregivers. A protective behavioral variation between fathers and mothers is suggested by Goldman et al. and Brussoni and Olsen $[10,13]$. Furthermore, the vaccination willingness rate was higher in our study if the child or their caregiver was vaccinated against seasonal influenza in the last year, and this finding was statistically significant.

In parallel with studies by Bell et al. and Goldman et al. $[8,10]$, protection of the child was the number one motivation for accepting vaccination, and fears of a vaccine's side effects along with its novelty were the two main reasons for rejecting vaccination. The next most common reason for accepting vaccination was protecting others and returning to normal life. The Ministry of Health in Saudi Arabia has provided scientifically based health information through their official website [14], and there have been local restrictions prohibiting misinformation on social media. A lack of trust in the healthcare system only represents a minor concern for Saudis, and the majority of those who accept vaccination for their children would do so if the health authorities recommended it, and this reflects their trust.

The participants were asked about their knowledge of COVID-19 protective measures; however, we failed to identify any relationship between parents' or caregivers' awareness and hesitancy toward vaccination. Our findings provide foundational data for future vaccination campaigns that address parents' and caregivers' concerns and misconceptions and provide up-to-date evidence-based information on the perceived risks of contracting COVID-19 and vaccinations for children.

This study is limited by the dynamic nature of the COVID-19 pandemic. The results of the study can only represent the population at the time that the survey was conducted. Furthermore, since there may be large differences in the impact of COVID-19 and healthcare system policies in different countries, it is not possible to generalize the results of this study to other parts of the world. Another limitation of this study is its inability to determine the extent of voluntary response bias. This voluntary response bias may have led to the predominance $(78.8 \%$ ) of female respondents in this study. This same issue was found in a previous study [8], where $95 \%$ of the respondents were female.

At the time of ending this questionnaire survey, there were 18 million Saudis who received at least one dose of their COVID-19 vaccination [15]. With a reported Saudi population of around 32.6 million adults in 2021, the proportion of vaccinated adults reaches up to 55\% [16]. This might indicate the presence of a voluntary response bias, in which those who did not approve of vaccination were more motivated to complete the survey. The response rate could not be obtained due to the method of questionnaire disturbance.

\section{Conclusions}

The willingness of parents and caregivers to vaccinate their children was low among the Saudi population at the time of this study. Concerns regarding the potential side effects and safety of the vaccines were the most common barriers to the willingness to vaccinate children. In contrast, protecting their children was the most common motivation for the uptake of vaccination. This study highlights the magnitude of the hesitancy of Saudi parents and caregivers for vaccinating their children. When the Saudi FDA grants approval for vaccinating children against COVID-19, a mass public education program is warranted to ensure acceptable nationwide vaccination rates. A structured awareness strategy will be needed to alleviate the fears and concerns of parents and caregivers.

\section{Additional Information \\ Disclosures}

Human subjects: Consent was obtained or waived by all participants in this study. King Saud University Medical City issued approval E-20-5558. This study was approved by the research ethics committee of the University Hospital (approval number E-20-5558). . Animal subjects: All authors have confirmed that this study did not involve animal subjects or tissue. Conflicts of interest: In compliance with the ICMJE uniform disclosure form, all authors declare the following: Payment/services info: All authors have declared that no financial support was received from any organization for the submitted work. Financial relationships: All authors have declared that they have no financial relationships at present or within the previous three years with any organizations that might have an interest in the submitted work. Other relationships: All authors have declared that there are no other relationships or activities that could appear to have influenced the submitted work.

\section{References}

1. Centers for Disease Control and Prevention. Get vaccinated!. (2021). Accessed: August 10, 2021: http://www.cdc.gov/coronavirus/2019-ncov/index.html.

2. World Health Organization. Coronavirus disease (COVID-19) pandemic . (2020). Accessed: August 10, 2021: http://www.who.int/emergencies/diseases/novel-coronavirus-2019.

3. Graham BS: Rapid COVID-19 vaccine development. Science. 2020, 368:945-946. 10.1126/science.abb8923

4. World Health Organization. COVID-19 vaccines. (2021). Accessed: February 28, 2021: http://www.who.int/emergencies/diseases/novel-coronavirus-2019/covid-19-vaccines.

5. World Health Organization. WHO target product profiles for COVID-19 vaccines . (2020). Accessed: August 


\section{Cureus}

10, 2021: http://www.who.int/docs/default-source/blue-print/who-target-product-profiles-for-covid-19vaccines.pdf?sfvrsn=1d5da7 ....

6. Goldman RD, Marneni SR, Seiler M, et al.: Caregivers' willingness to accept expedited vaccine research during the COVID-19 pandemic: a cross-sectional survey. Clin Ther. 2020, 42:2124-2133.

10.1016/j.clinthera.2020.09.012

7. Fadda M, Albanese E, Suggs LS: When a COVID-19 vaccine is ready, will we all be ready for it? . Int J Public Health. 2020, 65:711-712. 10.1007/s00038-020-01404-4

8. Bell S, Clarke R, Mounier-Jack S, Walker JL, Paterson P: Parents' and guardians' views on the acceptability of a future COVID-19 vaccine: a multi-methods study in England. Vaccine. 2020, 38:7789-7798. 10.1016/i.vaccine.2020.10.027

9. Thunstrom L, Ashworth M, Finnoff D, Newbold S: Hesitancy towards a COVID-19 vaccine and prospects for herd immunity. SSRN. 2020, 51.

10. Goldman RD, Yan TD, Seiler M, et al.: Caregiver willingness to vaccinate their children against COVID-19: cross sectional survey. Vaccine. 2020, 38:7668-7673. 10.1016/j.vaccine.2020.09.084

11. Al-Mohaithef M, Padhi BK: Determinants of COVID-19 vaccine acceptance in Saudi Arabia: a web-based national survey. J Multidiscip Healthc. 2020, 13:1657-1663. 10.2147/JMDH.S276771

12. Bish A, Yardley L, Nicoll A, Michie S: Factors associated with uptake of vaccination against pandemic influenza: a systematic review. Vaccine. 2011, 29:6472-6484. 10.1016/j.vaccine.2011.06.107

13. Brussoni M, Olsen L: Striking a balance between risk and protection: fathers' attitudes and practices toward child injury prevention. J Dev Behav Pediatr. 2011, 32:491-498. 10.1097/DBP.0b013e31821bd1f5

14. COVID-19 vaccine. (2021). Accessed: February 13, 2021: https://covid19awareness.sa/archives/10677.

15. Saudi Arabia COVID-19 vaccination stats. (2021). Accessed: July 26, 2021: https://covid19.moh.gov.sa/.

16. General Authority for Statistics, Kingdom of Saudi Arabia. Population estimates . (2021). Accessed: August 10, 2021: https://www.stats.gov.sa/en/43. 